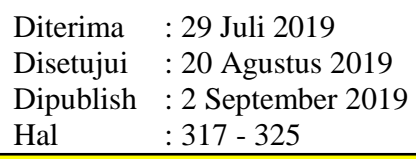

\title{
MANAJEMEN PEMBANGUNAN KEPENDUDUKAN: KOREKSI TERHADAP TEORI MALTHUS
}

\author{
LALU MUH. KABUL \\ Sekolah Tinggi Manajemen Informatika Komputer Mataram
}

e-mail: Kabullpp@yahoo.com

\begin{abstract}
ABSTRAK
Penelitian ini membahas manajemen pembangunan kependudukan dan kaitannya dengan koreksi teori Malthus.Metode penelitian yang digunakan adalah kuantitatif.Hasil penelitian menunjukkan bahwa teori Malthus hanya relevan sebelum Perang Dunia Kedua dimana untuk pengendalian penduduk sebagaimana dikemukakan Malthus dapat dilakukan dengan positive checks.Pasca Perang Dunia teori Malthus tidak lagi cocok dengan bukti lapangan.Oleh karena itu, akhirnya teori Malthus dikoreksi dan koreksinya adalah bukan positive checks yang diperlukan untuk pengendalian penduduk, melainkan pembangunan.Berkaitan dengan hal tersebut, maka diperlukan manajemen pembangunan kependudukan dalam bentuk Grand Design Pembangunan Kependudukan.
\end{abstract}

Kata kunci: Manajemen, kependudukan, teori Malthus

\section{ABSTRACT}

This study discusses population development management and it related to the correction of Malthus's theory. The study method used is quantitative. The result of study indicate on the one side the Malthus's theory is only relevant during before Second World War where according to Malthus that positives checks operate to control the population. On the other side after the Second World War Malthus's theory is not fit to the field evidence. Therefore, Malthus's theory is corrected and its correction is not positive checks that must be operated to control population, but development. In line with the reasons, it is needed a population development management, namelyPopulation Development Grand Design.

Keywords: Management, population, Malthus's theory

\section{PENDAHULUAN}

\section{Latar Belakang}

Thomas Malthus dalam karyanya Essay of the Principles of Population yang diterbitkan pada tahun 1798 menyatakan ketidakseimbangan antara pertumbuhan penduduk dan produksi pangan dimana peningkatan jumlah penduduk jauh lebih besar dari peningkatan produksi pangan yang dihasilkan alam, peningkatan penduduk mengikuti deret geometri atau deret ukur, sedangkan peningkatan produksi pangan mengikuti deret aritmatika atau deret hitung.Malthus menerbitkan karyannya untuk menyanggah pendapat yang dikemukakan William Godwin dan Marquis de Condorcet. Menurut Godwin seiring dengan berkembangnya pembangunan pertanian dan pembangunan industri, maka manusia akan mengalami peningkatan kesejahteraan dimana akan terjadi keseimbangan antara pertumbuhan penduduk dan produksi pangan. Hal senada dikemukakan Condorcet bahwa sejalan dengan pengembangan pendidikan dan kesehatan, maka kesejahteraan manusia juga bakal meningkat, tetapi pertumbuhan penduduk dan produksi pangan akantetap dalam keseimbangan (Avery John, 2015).

Karena karyanya ditujukan untuk menyanggah Godwin dan Condorcet, judul lengkap dari karya Malthus tersebut sebenarnya adalah Essay of the Principles of Population as it affects the future 
improvement of society with remarks on the speculations of Mr. Godwin, M. Condorcet, and other writers. Pernyataan Malthus mengenai peningkatan penduduk mengikuti deret ukur adalah berlandaskan pada data statistik penduduk Amerika Serikat yang pada waktu itu mengalami peningkatan dua kali lipat setiap 25 tahun yang mengikuti deret ukur sebagai berikut: 1,2,4,8,19,32,64,128,256,512,dan seterusnya. Dalam pada itu, pernyataan Malthus tentang peningkatan produksi pangan mengikuti deret hitung yakni berdasarkan produksi pertanian di Inggris pada waktu itu dimana setiap 25 tahun mengalami peningkatan mengikuti deret hitung sebagai berikut: 1,2,3,4,5,6,7,8,9,10, dan seterusnya (Malthus, 1798). Dalam pada itu, ratio (nisbah) antara produksi pangan dengan penduduk yang dinyatakan dalam rentang skor 0 sampai 100 dikenal indeks produksi pangan per kapita.Teori Malthus mengenai peningkatan penduduk mengikuti deret ukut dan peningkatan produksi mengikuti deret hitung dapat dinyatakan dalam indeks produksi pangan per kapita (IPPPK) sebagaimana ditampilkan pada tabel 1 (Sen, 1999).

Dari Tabel 1 diperoleh bahwa IPPPK pada 25 tahun pertama sebesar 100 dan setelah 50 tahun tetap sebesar 100 kemudian setelah 75 tahun turun menjadi 75 dan setelah satu abad turun lagi menjadi 50, setelah satu seperempat abad turun lagi menjadi 31 dan mengalami penurunan secara terus-menerus hingga menjadi 2 setelah dua setengah abad. Berkaitan dengan penurunan IPPPK tersebut, maka diperlukan tindakan pengendalian penduduk. Menurut Malthus pengendalian penduduk dapat dilakukan melalui dua cara, yaitu preventive cheks dan positive checks. Dalam pada itu, preventive checks dilakukan dengan moral restraint (pengekangan diri), yakni segala usaha untuk mengekang hawa nafsu dan vice yaitu pengurangan kelahiran, pengguguran kehamilan, dan penundaan usia kawin. Sedangkan, positive checks dilakukan melalui proses kematian seperti adanya berbagai penyakit dan epidemik, bencana alam, kelaparan, kekurangan pangan dan perang (Malthus, 1798).

Tabel 1. Teori Malthus dan Indeks Produksi Pangan Per Kapita (IPPPK)

\begin{tabular}{|l|c|c|c|c|c|c|c|c|c|c|}
\hline Produksi pangan (deret hitung) & 1 & 2 & 3 & 4 & 5 & 6 & 7 & 8 & 9 & 10 \\
\hline Jumlah penduduk (deret ukur) & 1 & 2 & 4 & 8 & 16 & 32 & 64 & 128 & 256 & 512 \\
\hline IPPPK & 100 & 100 & 75 & 50 & 31 & 19 & 11 & 6 & 4 & 2 \\
\hline
\end{tabular}

Sumber: Diolah dari Malthus (1798)

Teori Malthus tersebut memperoleh dukungan data empiris ketika penduduk Irlandia dilanda kelaparan secara meluas akibat gagalnya panen kentang pada tahun 1845 yang disebabkan oleh serangan penyakit, sehingga produksi makanan bagi penduduk sangat kurang. Gagalnya panen kentang ini menyebabkan sekitar 2 juta jiwa penduduk Irlandia mati kelaparan. Fenomena ini selaras dengan teori Malthus, yakni positive checks bahwa pengendalian penduduk dilakukan melalui proses kematian seperti adanya kelaparan. Pada tahun 1695 penduduk Irlandia mencapai 1 juta jiwa kemudian meningkat menjadi 6,8 juta jiwa pada tahun 1821 dan sekitar 8 juta lebih pada tahun 1845. Akibat gagalnya panen kentang pada tahun 1845, maka setelah tahun 1845 jumlah penduduk Irlandia dapat dikendalikan pada angka 4 juta jiwa (James Patricia, 2017).

Dengan berakhirnya perang Dunia Kedua pada tahun 1945, pasca perang semua negara di dunia termasuk negara-negara yang baru merdeka mulai melaksanakan pembangunan secara terencana dan dampak dari pembangunan tersebut adalah kenaikan IPPPK baik IPPPK Dunia maupun IPPPK negara-negara di kawasan Asia, Eropah dan Amerika Serikat dalam periode 1974-1997 sebagaimana ditampilkan pada Tabel 2 dan tahun 1979-1981 menjadi tahun dasar dengan indeks 100 (Sen, 1999).

Tabel 2. IPPPK Dunia Periode 1974-1997

\begin{tabular}{|l|c|c|c|c|c|}
\hline \multicolumn{1}{|c|}{ Kawasan } & $1974-1976$ & $1979-1981$ & $1984-1986$ & $1994-1996$ & $1996-1997$ \\
\hline Dunia & 97,4 & 100,0 & 104,4 & 108,4 & 111,0 \\
\hline Asia & 94,7 & 100,0 & 111,6 & 138.7 & 144,1 \\
\hline India & 96,5 & 100,0 & 110,7 & 128,7 & 130,5 \\
\hline China & 90,1 & 100,0 & 120,7 & 177,7 & 192,3 \\
\hline Eropah & 94,7 & 100,0 & 99,1 & 99,4 & 100,0 \\
\hline Amerika Serikat & 89,8 & 100,0 & 99,3 & 102,3 & 103,9 \\
\hline
\end{tabular}

Sumber: Sen (1999)

Kenaikan IPPPK pada Tabel 2 tersebut menunjukkan kondisi sebaliknya dengan teori Malthus yang sejalan dengan penurunan IPPPK sebagaimana ditampilkan pada tabel 1 dan oleh karena itu, maka teori Malthus perlu dikoreksi.Koreksi terhadap terhadap teori Malthus adalah bukan positive checks yang diperlukan untuk pengendalian penduduk, melainkan pembangunan(development). 
Menurut Amartya Sen (1999), peraih nobel ekonomi tahun 1998 bahwa pembangunan itulah yang menjadi "kontrasepsi" dalam pengendalian penduduk. Pembangunan dimaksud meliputi pembangunan ekonomiyang dikemukakan oleh Becker, peraih nobel ekonomi pada tahun 1992 (Becker, 1992) dan pembangunan sosial (Sen, 1999). Terdapat 5 (lima) negara di dunia yang memiliki jumlah penduduk terbesar, yaitu China, India, Amerika Serikat dan Indonesia (UNFPA, 2018).Salah satu provinsi yang memiliki jumlah penduduk terbesar di Kawasan Timur Indonesia adalah provinsi Nusa Tenggara Barat (NTB).

Permasalahannya adalah apakah koreksi terhadap teori Malthus bahwa untuk pengendalian penduduk yang diperlukan bukanlah positivechecks melainkan pembangunan juga memiliki relevansi dengan bukti lapangan di NTB dan apa saja komponen pembangunan sosial ekonomi yang berpengaruh terhadap pengendalian penduduk serta apa manajemen kependudukan yang perlu dirumuskan bagi pembangunan kependudukan. Berkaitan dengan hal tersebut, maka perlu dilakukan penelitian dan penelitian ini dilaksanakan di NTB.

\section{Rumusan Masalah}

Rumusan masalah dalam penelitian ini adalah sebagai berikut: (1) apakah koreksi teori Malthus memiliki relevansi dengan bukti lapangan, (2) apa saja komponen pembangunan sosial ekonomi yang berpengaruh terhadap pengendalian penduduk, (3) apa strategi manajemen kependudukan yang perlu dirumuskan bagi pembangunan kependudukan.

\section{Tujuan Penelitian}

Penelitian ini dilaksanakan dengan tujuan sebagai berikut: (1) menganalisis relevansi koreksi teori Malthus dengan bukti lapangan, (2) menganalisis komponen pembangunan sosial ekonomi yang berpengaruh terhadap pengendalian penduduk, (3) merumuskan strategi manajemen kependudukan yang diperlukan bagi pembangunan kependudukan.

\section{METODE PENELITIAN}

\section{Metode Pendekatan}

Dalam penelitian ini digunakan pendekatan kuantitatif (Kathori CR \& Gaurav, 2010).Di NTB terdapat 10 kabupaten/kota kemudian secara purposive sampling diambil 1 (satu) kabupaten sampel dengan pertimbangan jumlah penduduk terbanyak, yaitu Kabupaten Lombok Timur.Dalam penelitian ini digunakan sampel sebanyak 167PUS (pasangan usia subur).

Sumber data dalam penelitian ini meliputi data primer dan data sekunder.Data primer diperoleh melalui wawancara dengan PUS sampel dengan berpedoman pada kusioner.Sedangkan data sekunder adalah data yang diperoleh dari Badan Pusat Statistik (BPS) dan dokumen-dokumen relevan lainnya yang terkait dengan penelitian ini.

\section{Variabel dan Analisis Data}

Variabel dalam penelitian ini meliputi koreksi teori Malthus, pengendalian penduduk dan pembangunan sosial ekonomi,strategi manajemen kependudukan. Variabel koreksi teori Malthus dianalisis menggunakan IPPPK (Sen, 1999).Variabel pengendalian penduduk dan pembangunan sosial ekonomi dianalisis menggunakan regresi logistik biner atau dikotomi, yakni sebuah analisis yang digunakan untuk menjelaskan hubungan pengendalian penduduk sebagai variabel respon (variabel terikat)dan pembangunan sosial ekonomi sebagai variabel prediktor (variabel bebas).Variabel respon dalam penelitian bersifat biner atau dikotomik yang terdiri dari dua kategori yaitu "sukses" $(\mathrm{y}=1)$ dan "gagal" $(\mathrm{y}=0)$. Variabel prediktor berupa seperangkat variabel dummy.Model persamaan regresi logistik, adalah sebagai berikut (Demaris, 2017):

$\operatorname{logit}(\mathrm{y})=\ln ($ odds $)=\ln \frac{\pi(\mathrm{x})}{1-\pi(\mathrm{x})}=(\beta \mathrm{o}+\beta 1 \mathrm{x} 1+\beta 2 \times 2+\ldots+\beta \mathrm{nxn})$ 
Dimana ln merupakan logaritma natural dengan bilangan pokok adalah konstanta Euler yakni e=2,71828 dan $\pi=$ peluang (y=kejadian sukses " 1 " atau gagal " 0 " $\mid \mathrm{X}=\mathrm{x}$ ) dan transformasi logit dari $\pi(\mathrm{x})$ adalah sebagai berikut (Press SJ \& Wilson S., 2015):

$\mathrm{g}(\mathrm{x})=\beta \mathrm{o}+\beta 1 \mathrm{x} 1+\beta 2 \mathrm{x} 2+\ldots+\beta \mathrm{nxn}$

Variabel respon dalam bentuk biner atau dikotomik, yaitu:

$y=\pi(x)+\epsilon i$

1. Jika $\mathrm{y}=1$, maka $\epsilon \mathrm{i}=1-\pi(\mathrm{x})$ dengan peluang $\pi(\mathrm{x})$

2. Jika $\mathrm{y}=0$, maka $\epsilon \mathrm{i}=-\pi(\mathrm{x})$ dengan peluang $1-\pi(\mathrm{x})$

Dalam penelitian ini indikator dari pengendalian penduduk sebagai variabel respon adalah jumlah anak ( $\hat{\mathrm{g}}$ ) yang terdiri dari dua kategori yaitu jumlah anak ideal paling banyak 2 anak dan jumlah anak lebih dari 2 dan variabel prediktor yaitu pembangunan sosial ekonomi terdiri dari tiga indikator yaitu ekonomi (pendapatan) dan sosial (pendidikan wanita dan status bekerja wanita) dan indikator variabel prediktor dinyatakan dalam variabel dummy dengan model persamaan regresi logistik sebagai berikut:

$\hat{g}(x)=\beta 0+\beta 1 \times 1+\beta 2 \times 2+\beta 3 \times 3$

dimana: $\mathrm{x} 1$ = variabel dummy pendapatan dibawah garis kemiskinan (diatas garis kemiskinan*)

$\mathrm{x} 2$ = variabel dummy pendidikan wanita pernah bersekolah/tamat SD $\left(>\mathrm{SD}^{*}\right)$

x3 = variabel dummy status bekerja wanita kategori tidak bekerja (bekerja*)

Keterangan: *) kategori referensi

Untuk mengetahui pengaruh variabel prediktor secara parsial terhadap variabel respon digunakan Uji Wald pada taraf signifikansi $\alpha$ 0,05 (Demaris, 2017). Dalam pada itu, untuk mengetahui pengaruh variabel prediktor secara simultan terhadap variabel respon dilakukan pengujian "overall model", dengan Uji Likelihood $\chi^{2}$ (Chi-square) pada taraf signifikansi $\alpha 0,05$ (Press SJ. \& Wilson S., 2015) Selain itu, untuk mengetahui apakah data empiris cocok atau sesuai dengan model dilakukan pengujian "goodness of fit", dengan Uji Hosmer \& Lemeshow (Hosmer DW \& Lemeshow S., 2000).Untuk mengetahui ada atau tidaknya multikolinearitas dalam model regresi logistik tersebut digunakan Variance Inflation Factor (VIF). Disisi lain, strategi manajemen kependudukan dianalisis dengan menggunakan Field Force Analysis (Kathori CR \& Gaurav G, 2010).

\section{HASIL DAN PEMBAHASAN}

\section{Koreksi Teori Malthus}

Sebelumnya telah dibahas bahwa teori Malthus sejalan dengan penurunan IPPPK dan berkaitan dengan penurunan IPPPKtersebut, maka diperlukan tindakan pengendalian penduduk. Menurut Malthus pengendalian penduduk dapat dilakukan melalui dua cara, yaitu preventive cheks dan positive checks. Menurut Malthus pengendalian penduduk dengan positive checks dilakukan melalui proses kematian seperti adanya berbagai penyakit dan epidemik, bencana alam, kelaparan, kekurangan pangan dan perang. Teori Malthus memperoleh dukungan data empiris ketika penduduk Irlandia dilanda kelaparan secara meluas akibat gagalnya panen kentang pada tahun 1845 yang disebabkan oleh serangan penyakit, sehingga produksi makanan bagi penduduk sangat kurang. Gagalnya panen kentang ini menyebabkan sekitar 2 juta jiwa penduduk Irlandia mati kelaparan. Fenomena ini selaras dengan teori Malthus, yakni positive checks bahwa pengendalian penduduk dilakukan melalui proses kematian seperti adanya kelaparan.

Teori Malthus juga relevan dengan bukti lapangan di Pulau Lombok NTB ketika Lombok berada di bawah kekuasaan kolonial Belanda dimana data empiris menunjukkan IPPPK(Padi) mengalami penurunan dalam periode 1900-1940 sebagaimana ditampilkan pada tabel 3 dimana penurunan IPPK (Padi) ini sejalan dengan teori Malthus. Pengendalian penduduk dengan positive checkssebagaimana dikemukakan Malthus 
yakni melalui proses kematian seperti adanya berbagai penyakit dan kelaparan, kekurangan pangan juga terjadi di Lombok pada waktu itu. Penyakit cacar yang melanda Lombok pada tahun 1912 menyebabkan ribuan orang meninggal. Disisi lain, pada tahun 1918 Lombok dilanda berbagai jenis penyakit seperti influenza, malaria, disentri dan kolera yang menyebabkan paling tidak 36.042 orang meninggal atau sekitar 5,9 persen dari jumlah penduduk Lombok pada waktu itu.Pada tahun 1938, Lombok dilanda kelaparan secara meluas dan penyakit busung lapar (van der Kraan, 1976).

Tabel 3. IPPPK Pulau Lombok (Padi) Periode 1900-1940

\begin{tabular}{|l|c|c|c|c|}
\hline & $1900-1910$ & $1911-1920$ & $1921-1930$ & $1931-1940$ \\
\hline Konsumsi padi (gr/kapita/hari) & 395 & 365 & 353 & 300 \\
\hline IPPPK & 100,00 & 92,41 & 89,37 & 75,95 \\
\hline
\end{tabular}

Sumber: Diolah dari van der Kraan (1976)

Lombok akhirnya melepaskan diri dari kekuasaan kolonial Belanda setelah proklamasi kemerdekaan Indonesia pada tanggal 17 Agustus 1945.Perang Dunia Kedua juga berakhir pada tahun 1945.Pasca kemerdekaan pemerintah Indonesia melaksanakan pembangunanuntuk meningkatkan kesejahteraan rakyat termasuk rakyat Lombok.Dalam pembangunan pertanian misalnya, dimulai pada tahun 1958 dengan program peningkatan produksi pangan (padi) melalui pendirian Badan Perusahaan Produksi Bahan Makanan dan Pembukaan Tanah (BPMT) dibawah Departemen Pertanian. Peningkatan produksi padi (beras) yang diusahakan oleh BPMT tersebut dilakukan melalui intensifikasi dan ekstensifikasi.Untuk menggerakkan partisipasi petani secara massal dalam program intensifikasi pada tahun 1959 dibentuk Komando Operasi Gerakan Tekad Makmur (KOGM-Inpres 1/1959) (Abdul Adjid, 1985).

Kemudian pada tahun 1965 untuk menyempurnakan KOGM dilaksanakan program Bimbingan Massal (Bimas) yang merupakansistem bimbingan penerapan panca usaha oleh para petani melalui penyuluhan yang dilengkapi dengan paket sarana produksi, perkreditan dan pemasaran hasil. Pada tahun 1968 program Bimas tersebut disempurnakan melalui penerapan paket agro-teknologi "Revolusi Hijau" berupa bibit unggul baru, pupuk, pestisida dalam kegiatan intensifikasi pertanian secara massal (Inmas) kemudian disempurnakan menjadi intensifikasi khusus (Insus) sejak tahun 1979 dan akhirnya Indonesia berhasil mencapai swasembada pangan (padi) sejak tahun 1980 (Abdul Adjid, 1985). Keberhasilan swasembada pangan di Lombok, khususnya Lombok Timur ditunjukkan oleh kenaikan IPPPK (Padi dan Jagung) pada tabel 4 yang menunjukkan kondisi sebaliknya dengan teori Malthus.Artinya teori Malthus di Lombok Timur tidak lagi memperoleh dukungan data empiris dengan kenaikan IPPPK(Padi dan Jagung) sebagaimana ditampilkan pada tabel 4 (BPS Lombok Timur, 2018a).Oleh karena itu, maka teori Malthus akhirnya dikoreksi dan koreksinya adalah bukan positive checks yang diperlukan untuk pengendalian penduduk, melainkan pembangunan (Sen, 1999).

Tabel 4. IPPPK Lombok Timur (Padi dan Jagung) Periode 2010-2015

\begin{tabular}{|l|c|c|c|}
\hline \multicolumn{1}{|c|}{ Komoditas } & $2010-2011$ & $2012-2013$ & $2014-2015$ \\
\hline Padi & 100,00 & 107,13 & 112,50 \\
\hline Jagung & 100,00 & 109,03 & 129,33 \\
\hline
\end{tabular}

Sumber: Diolah dari BPS Lombok Timur (2018a)

\section{Pengendalian Penduduk}

Berdasarkan Tabel 5 diperoleh hubungan antara pengendalian penduduk, yakni jumlah anak [ $\mathrm{g}(\mathrm{x})]$ sebagai variabel respon dengan variabel prediktor, yaitu pendapatan (x1), pendidikan wanita (x2) dan status wanita bekerja (x3) dapat dinyatakan dalam model persamaan regresi logistik berikut: $\operatorname{logit} \hat{g}(\mathrm{x})=0,514-0$, $293)^{*} x 1-(0,311)^{*} \times 2-(0,405)^{*} \times 3$. Dari Uji Wald diperoleh bahwa variabel prediktor secara parsial memiliki pengaruh signifikan terhadap variabel respon dimana masing-masing ditunjukkan oleh signifikansi pendapatan $(\mathrm{x} 1)$ sebesar $0,030(\mathrm{p}=0,030<0,05)$ kemudian signifikansi pendidikan wanita $(\mathrm{x} 2)$ sebesar 0,023 $(\mathrm{p}=0,023<0,05)$ dan signifikansi status wanita bekerja $(\mathrm{x} 3)$ sebesar $0,029(\mathrm{p}=0,029<0,05)$. 
Tabel 5. Hasil Analisis Regresi Logistik

\begin{tabular}{|l|c|c|c|c|c|}
\hline Prediktor & $\mathrm{B}$ & $\mathrm{Se} \beta$ & Wald & $\mathrm{df}$ & $\mathrm{p}$ \\
\hline Konstanta & 0,514 & 0,122 & 1,497 & 2 & 0,030 \\
\hline Pendapatan (x1) & $-0,293$ & 0,025 & 4,899 & 2 & 0,023 \\
\hline Pendidikan wanita (x2) & $-0,311$ & 0,039 & 5,453 & 2 & 0,027 \\
\hline Status wanita bekerja (x3) & $-0,405$ & 0,017 & 4,971 & 2 & 0,029 \\
\hline Test & $\chi^{2}$ & $\mathrm{df}$ & $\mathrm{p}$ \\
\hline Overall model evaluation & & 11,261 & 3 & 0,035 \\
\hline Likelihood ratio test & & & \\
\hline Goodness of fit test & 7,963 & 8 & 0,475 \\
\hline Hosmer \& Lemeshow & & & & \\
\hline Cox and Snell $\mathrm{R}^{2}$ & $=0,769$ & & & \\
\hline Nagelkerke $\mathrm{R}^{2}$ & $=0,895$ &
\end{tabular}

Sumber: Data pimer (diolah)

Dari Uji Likelihood sebagaimana ditampilkan pada Tabel 5 diperoleh bahwa semua variabel prediktor secara simultan memiliki pengaruh signifikan terhadap variabel respon yang ditunjukkan oleh signifikansi sebesar $0,035(\mathrm{p}=0,035<0,05)$. Data empiris yakni data primer yang diperoleh dalam penelitian ini cocok atau sesuai dengan model; artinya tidak ada perbedaan antara model dengan data sehingga model dapat dinyatakan "fit" yang ditunjukkan oleh Uji Hosmer \& Lemeshow sebesar 7,963 dengan signifikansi sebesar 0,475 ( $\mathrm{p}=0,475>0,05)$.Disisi lain, berdasarkan Cox and Snell diperoleh $\mathrm{R}^{2}$ sebesar 0,769 artinya kontribusi ketiga variabel prediktor, yaitu pendapatan $(\mathrm{x} 1)$, pendidikan wanita (x2) dan status wanita bekerja (x3) terhadap pengendalian penduduk, yakni jumlah anak $[\hat{\mathrm{g}}(\mathrm{x})]$ sebagai variabel respon sebesar 76,90 persen dan kontribusi ketiga variabel prediktor tersebut lebih besar lagi berdasarkan $\mathrm{R}^{2}$ Negelkerke yakni sebesar 89,50 persen. Berdasarkan Uji Multikolinearitas diperoleh nilai VIF untuk masing-masing variabel prediktor, yaitu pendapatan (x1) sebesar 5,787 kemudian pendidikan wanita (x2) sebesar 6,759 dan status wanita bekerja (x3) sebesar 7,791. Nilai ketiga variabel prediktor tersebut kurang dari $10(<10)$, sehingga dengan demikian tidak terjadi multikolinearitas.

Dari model persamaan regresi diperoleh bahwa pendapatan (x1) memiliki hubungan negatif dengan jumah anak $[\hat{\mathrm{g}}(\mathrm{x})]$, artinya makin tinggi pendapatan, maka jumlah anak yang dilahirkan makin sedikit; demikian sebaliknya.Demikian pula dengan pendidikan wanita (x1) memiliki hubungan negatif dengan jumlah anak $[\hat{\mathrm{g}}(\mathrm{x})]$ dimana makin tinggi pendidikan wanita, maka jumlah anak yang dilahirkan makin sedikit; demikian sebaliknya.Status bekerja wanita (x3) juga memiliki hubungan negatif dengan jumlah anak $[\hat{\mathrm{g}}(\mathrm{x})]$ yakni makin wanita tinggi waktu yang dicurahkan oleh wanita untuk bekerja, maka jumlah anak makin sedikit; demikian pula sebaliknya.

\section{Manajemen Pembangunan Kependudukan}

Uraian-uraian sebelumnya menunjukkan bahwa teori Malthus berlaku sebelum Perang Dunia Kedua dimana untuk pengendalian penduduk sebagaimana dikemukakan Malthus dapat dilakukan dengan positive checks yakni melalui proses kematian seperti adanya berbagai penyakit dan epidemik, bencana alam, kelaparan, kekurangan pangan dan perang.Pasca Perang Dunia teori Malthus tidak relevan lagi dengan kondisi lapangan karena tidak cocok dengan bukti lapangan, yakni data empiris.Oleh karena itu, akhirnya teori Malthus dikoreksi dan koreksinya adalah bukan positive checks yang diperlukan untuk pengendalian penduduk, melainkan pembangunan. Dalam pada itu, berdasarkan hasil analisis regresi logistik diperoleh bahwa baik pembangunan ekonomi (pendapatan) maupun pembangunan sosial (pendidikan wanita dan status bekerja wanita) memiliki pengaruh signifikan terhadap pengendalian penduduk (jumlah anak).

Dari sisi ekonomi, makin tinggi pendapatan keluarga maka pilihannya bukanlah pada kuantitas anak, melainkan pada kualitas anak, sehingga seiring dengan meningkatnya pendapatan keluarga mengambil keputusan untuk membentuk keluarga kecil dengan sedikit anak (Becker, 1992). Dari sisi sosial yakni pendidikan wanita bahwa pendidikan yang diperoleh wanita dapat memengaruhi pola pikir wanita dalam pengambilan keputusan terkait fertilitasnya, artinya makin tinggi pendidikan wanita maka jumlah anak yang dilahirkan makin sedikit (Dreze J and Mamta M, 1999). Dari sisi sosial lainnya yakni satus bekerja wanita, pekerjaan wanita berpengaruh terhadap fertilitasnya dimana wanita yang mencurahkan waktunya bekerja di luar rumah tidak ingin waktu kerjanya terganggu karena harus diselingi dengan mengurus banyak anak, sehingga wanita bekerja memutuskan untuk melahirkan sedikit anak (Easterlin, 2013 ;Ruri Indrasari dan Risni J.Y., 2012). 
Pengaruh signifikan pembangunan sosial ekonomi terhadap pengendalian penududuk (jumlah anak) di Lombok Timur tampak dari turunnya laju petumbuhan Lombok Timur antar sensus yakni dari 2,19 persen dalam periode 1971-1980 kemudian turun menjadi 1,78 persen dalam periode 1980-1990 dan turun lagi menjadi 1,69 persen dalam periode 1990-2000 dan 0,78 persen dalam periode 2000-2010 (BPS Lombok Timur, 2018a). Namun demikian penduduk Lombok Timur belum tumbuh seimbang. Disisi lain kualitas, tingkat kesehatan, dan kesejahteraan penduduk pun masih belum memadai. Pada tahun 2040 diharapkan terwujudnya penduduk berkualitas tinggi, tumbuh seimbang, sejahtera, sehat, cerdas ,maju, mandiri, beriman, bertakwa, berakhlak mulia, memiliki etos kerja tinggi, dan serasi dengan daya dukung alam dan daya tampung lingkungan.

Untuk itu, maka diperlukan manajemen pembangunan kependudukan dalam bentuk Grand Design Pembangunan Kependudukan (GDPK) 2015-2040.GDPK 2015-2040 selaras dengan Undang Undang Nomor 52 Tahun 2009 tentang Perkembangan Kependudukan dan Pembangunan Keluarga yang kemudian diatur Peraturan Presiden Nomor 153 Tahun 2014. GDPK 2015-2040 tersebut juga selaras dengan agenda Sustainable Development Goals( SDGs) 2015-2030, yakni penduduk (people), daya tampung bumi (planet), dan kesejahteraan (prosperity)(United Nations, 2015). Tahun 2015 digunakan sebagai kondisi awal karena SDGs dimulai pada tahun 2015 dan informasi serta data kependudukan yang tersedia untuk mendukung kondisi awal tersebut adalah data Survei Penduduk Antar Sensus (SUPAS) 2015. GDPK 2015-2040 terdiri dari 5 (lima)pilar strategis, yaitu pengendalian kuantitas penduduk, peningkatan kualitas penduduk penduduk, pembangunan keluarga, penataan persebaran dan pengarahan mobilitas, penataan administrasi kependudukan.

Pengendalian kuantitas penduduk menjadi penting dimana pada tahun 2015 rasio ketergantungan (dependency ratio) Lombok Timur sebesar 55,49 belum mencapai bonus demografi. Bonus demografi dicapai pada rasio ketergantungan dibawah 50 (Ogawa et al, 2009). Dalam pada itu, dari $10 \mathrm{kabupaten/kota}$ di NTB terdapat 3 kabupaten yang belum mencapai bonus demografi, yaitu Lombok Timur, Sumbawa Barat, dan Dompu. Bonus demografi, yakni dengan berkurangnya jumlah penduduk usia tidak produktif, maka biaya yang ditujukan untuk mengurus penduduk tidak produktif dapat dialihkan untuk investasi dalam kegiatan ekonomi dan percepatan pembangunan. Bonus demografi lainnya, diperolehnya keuntungan ekonomi yang disebabkan oleh makin besarnya jumlah tabungan dari penduduk usia produktif sehingga dapat memicu investasi dan pertumbuhan ekonomi dimana pertumbuhan ekonomi merupakan salah satu tujuan SDGs 2015. Kedepan, Lombok Timur akan kehilangan kesempatan (window of opportunity) untuk memperoleh bonus demografi, jika kuantitas penduduk tidak dikendalikan.

Dengan menggunakan Indeks Pembangunan Manusia (IPM) sebagai indikator, kualitas penduduk Lombok Timur masih tergolong dalam kategori "sedang” dengan nilai IPM sebesar 62,83 pada tahun 2015. Kisaran nilai IPM untuk kategori sedang adalah 50 hingga 70. Nilai IPM Lombok Timur pada pada tahun 2015 berada pada peringkat ke-8 dari 10 kabupaten/kota di NTB.IPM merupakan indeks komposit dari dimensi kesehatan (umur panjang dan sehat), dimensi pendidikan (pengetahuan dan keterampilan), dan dimensi ekonomi (kehidupan yang layak) (BPS Lombok Timur, 2018b).Ketiga dimensi tersebut, yakni dimensi kesehatan, pendidikan, dan ekonomi merupakan tujuan dari SDGs 2015-2030. Dalam pada itu, ketiga dimensi tersebut juga merupakan misi pembangunan Lombok Timur 2018-2023 sebagai tertuang dalam Rencana Pembangunan Jangka Menengah Daerah (RPJMD) Lombok Timur 2018-2023. Berkaitan dengan nilai IPM Lombok Timur pada tahun 2015 yang masih tergolong dalam kategori sedang, maka kedepan diperlukan strategi peningkatan kualitas penduduk.

Disisi lain, di Lombok Timur pada tahun 2015 terdapat sebanyak 407.301 keluarga meliputi Keluarga Pra Sejahtera (Pra KS) sebesar 31,09 persen, Keluarga Sejahtera I (KS I) sebesar 42,20 persen, Keluarga Sejahtera II (KS II) sebesar 18,90 persen, Keluarga Sejahtera III (KS III) sebesar 7,10 persen, dan Keluarga Sejahtera III Plus (KS III Plus) sebesar 0,71 persen. Dengan menggunakan tiga kategori kesejahteraan keluarga, maka keluarga dengan tingkat kesejahteraan rendah (Pra KS dan KS I) sebesar 73,29 persen, keluarga dengan tingkat kesejahteraan sedang (KS II dan KS III) sebesar 26,00 persen dan keluarga dengan tingkat kesejahteraan tinggi (KS III Plus) sebesar 0,71 persen. Ini menggambarkan bahwa sebagian besar keluarga di Lombok Timur (73,29 persen) pada tahun 2015 tergolong dalam tingkat kesejahteraan rendah. Kedepan, pembangunan keluarga merupakan strategi untuk meningkatkan kesejahteraan keluarga.

Persebaran penduduk di Lombok Timur tidak merata dimana terdapat empat kecamatan yang memiliki jumlah penduduk terbanyak, yaitu Masbagik (100.669 jiwa), Aikmel (99.412 jiwa), Pringgabaya (94.962 jiwa), dan Selong (91.481 jiwa). Jumlah penduduk keempat kecamatan tersebut mencapai 386.524 jiwa atau sekitar sepertiga dari penduduk Lombok Timur dan kecamatan dengan jumlah penduduk paling sedikit adalah Sembalun dengan jumlah penduduk sekitar 20.050 jiwa. Dari sisi mobilitas, Tenaga Kerja Indonesia (TKI) asal Lombok Timur umumnya melakukan mobilitas ke keluar negeri untuk bekerja sebagai buruh 
kasar (unskilled labor) dengan negara tujuan utama Malaysia. Pada tahun 2015 terdapat 13.594 orang TKI asal Lombok Timur terdiri dari laki-laki sebanyak 12.724 orang ( 93,60 persen) dan perempuan sebanyak 870 orang (6,40 persen) yang diberangkatkan untuk bekerja di luar negeri dengan negara tujuan utama adalah Malaysia (94,77 persen) dan lainnya (5,23 persen) adalah negara-negara Arab, Taiwan, Singapura, dan Brunei Darussalam (BPS Lombok Timur, 2018b). Upah merupakan motif ekonomi yang mendorong TKI asal Lombok Timur bermigrasi dimana upah di Malaysia mencapai 2 hingga 3 kali lebih tinggi dibandingkan upah di Lombok Timur. Dalam pada itu, di luar negeri TKI laki-laki asal Lombok Timur bekerja sebagai buruh kasar (unskilled labor) pada perkebunan, konstruksi, pabrik. Sementara TKI perempuan bekerja sebagai pembantu rumah tangga, pelayanan, dan lain-lain. Beragam permasalahan yang terjadi pada TKI asal Lombok Timur di Malaysia seperti TKI yang tidak memiliki dokumen resmi atau TKI illegal, pemalsuan dokumen, penganiayaan oleh majikan. Berkaitan dengan permasalahan tersebut, maka strategi kedepan diperlukan penataan persebaran dan pengarahan mobilitas.

Dalam administrasi kependudukan, penggunaan Sistem Informasi Administrasi Kependudukan (SIAK) sebenarnya tidak hanya menghasilkan KTP elektronik (e-KTP), tetapi juga kartu keluarga, akta kelahiran termasuk data migrasi masuk dan migrasi keluar. Dalam pada itu, karena SIAK tidak memuat data migrasi masuk dan data migrasi keluar, sehingga sulit untuk mengetahui berapa jumlah penduduk Lombok Timur yang telah berpindah keluar dari Lombok Timur dan jumlah penduduk dari luar yang berpindah masuk ke Lombok Timur. Pelayanan dokumen kependudukan terkonsentrasi di ibu kota kabupaten, meskipun telah didesentralisasikan ke kecamatan, namun masih terdapat berbagai permasalahan. Kedepan diperlukan strategi yang berkaitan dengan penataan administrasi kependudukan.

\section{SIMPULAN DAN SARAN}

\section{Simpulan}

1. Teori Malthus berlaku sebelum Perang Dunia Kedua dimana untuk pengendalian penduduk sebagaimana dikemukakan Malthus dapat dilakukan dengan positive checks yakni melalui proses kematian seperti adanya berbagai penyakit dan epidemik, bencana alam, kelaparan, kekurangan pangan dan perang. Pasca Perang Dunia teori Malthus tidak relevan lagi dengan kondisi lapangan karena tidak cocok dengan bukti lapangan, yakni data empiris. Oleh karena itu, akhirnya teori Malthus dikoreksi dan koreksinya adalah bukan positive checks yang diperlukan untuk pengendalian penduduk, melainkan pembangunan.

2. Pembangunan ekonomi (pendapatan) maupun pembangunan sosial (pendidikan wanita dan status bekerja wanita) memiliki pengaruh signifikan terhadap pengendalian penduduk (jumlah anak). Pendapatan memiliki hubungan negatif dengan jumah anak, artinya makin tinggi pendapatan, maka jumlah anak yang dilahirkan makin sedikit; demikian sebaliknya. Demikian pula dengan pendidikan wanita memiliki hubungan negatif dengan jumlah anak dimana makin tinggi pendidikan wanita, maka jumlah anak yang dilahirkan makin sedikit; demikian sebaliknya. Status bekerja wanita juga memiliki hubungan negatif dengan jumlah anak yakni makin wanita tinggi waktu yang dicurahkan oleh wanita untuk bekerja, maka jumlah anak makin sedikit; demikian pula sebaliknya.

3. Pada tahun 2040 diharapkan terwujudnya penduduk berkualitas tinggi, tumbuh seimbang, sejahtera, sehat, cerdas ,maju, mandiri, beriman, bertakwa, berakhlak mulia, memiliki etos kerja tinggi, dan serasi dengan daya dukung alam dan daya tampung lingkungan. Untuk itu, maka diperlukan manajemen pembangunan kependudukan dalam bentuk Grand Design Pembangunan Kependudukan (GDPK) 2015-2040. GDPK 2015-2040 terdiri dari 5 (lima) pilar strategis, yaitu pengendalian kuantitas penduduk, peningkatan kualitas penduduk penduduk, pembangunan keluarga, penataan persebaran dan pengarahan mobilitas, penataan administrasi kependudukan.

\section{Saran-Saran}

1. Koreksi teori Malthus dalam penelitian ini sebaiknya digunakan sebagai materi pembelajaran dalam Sekolah Siaga Kependudukan agar peserta didik tidak hanya mengenal teori Malthus, melainkan juga koreksi teori Malthus.

2. Penyusunan Grand Design Pembangunan Kependudukan (GDPK) di tingkat provinsi maupun kabupaten/kota sebaiknya dilakukan oleh Tim Koordinasi yang melibatkan Organisasi Perangkat Daerah (OPD) terkait dan pemangku kepentingan (stakeholders) lainnya. 
3. Sebaiknya tugas Tim Koordinasi tidak hanya sebatas menyusun GDPK, tetapi juga mengarahkan OPD terkait agar GDPK tersebut oleh masing-masing OPD terkait dituangkan kedalam rencana strategis (renstra) dan rencana kerja (renja) tahunan.

\section{DAFTAR PUSTAKA}

Abdul Adjid Dudung, 1985. Pola Partisipasi Masyarakat Pedesaan Dalam Pembangunan Pertanian Berencana. Penerbit Orba Shakti, Bandung

Avery John, 2015. Malthus's Essay on the Principle of Population. H.C. Ørsted Institute, University of Copenhagen, Denmark.

Becker Gary S., 1992. The Economic Way of Looking at Life. Nobel Lecture, December 1992. Departement of Economics, University of Chicago, IL.60637, USA

BPS Lombok Timur, 2018a.Statistik Daerah Kabupaten Lombok Timur 2018.Selong.

BPS Lombok Timur, 2018b.Lombok Timur Dalam Angka 2018.Selong.

Demaris, A, 2017.Logit Modeling:Practical Application. Newbury Park,CA:Sage.

Easterlin, R.A, 2013. Population and Economic Change in Developing Countries. University of Chicago, Chicago.

Hosmer, D.W.\& Lemeshow, S., 2000. Applied Logistic Regression. Second edition, John Wiley and Sons, Inc, New York, USA.

James, Patricia, 2017.Population Malthus, his Life and Times. Routledge, London.

Jean Dreze and Mamta Murthi, 1999.Female Literacy and Fertility:Recent Census Evidence from India. Mimeographed, Centre for History and Economics, King's College, Cambridge

Kathori CR \& Gaurav G., 2010.Research Methodology, Methods and Technique. New Age International Publishing, New Delhi.

Malthus, Thomas, 1798. An Essay on the Principle of Population, as it affects the future improvement of society with remarks on the specualtions of Mr.Godwin,M.Condorcet, and other writers. J.Johnson, London.

Ogawa Naohiro et al, 2009. Some New Insight Into the Demographic Transition and Changing Age Structure in the ESCAP Region. Asia-Pacific Population Journal, Vol.24 No.1 April 2009:87-116.

Press, S.J \& Wilson, S., 2015.Choosing Between Logistic Regression and Discriminant Analysis. Journal of the American Statistical Association,73:699-705.

Ruri Indraswari Risa dan Risni, J.Y., 2017.Faktor-Faktor Yang Memengaruhi Penundaan

Kelahiran Anak Pertama di Wilayah Perdesaan Indonesia: Analisis Data SDKI 2012. Jurnal Kependudukan Indonesia, Vol.12 No.1 Juni 2017:1-12.

Sen, Amartya, 1999. Development As Freedom. Oxford University Press, Oxford.

UNFPA, 2018.The Power of Choice: Reproductive Rights and the Demographic Transition.

UNFPA, the United Nations Population Fund, New York, USA.

United Nations, 2015.Transforming Our World, The 2030 Agenda for Sustainable Development. United Nations, New York, USA.

van der Kraan Alfons, 1976. Selaparang Under Balinese and Dutch Rule: A History of Lombok1870-1940. $\mathrm{PhD}$ Thesis, Australian National University, Canberra. 